\title{
Does type and number of used substances affect the severity of illness in patients with substance use disorders?
}

\author{
Maha Ali Hassan, Mohamed Ayman Abdelhameed, Mostafa Mahmoud Abd El-Naem and \\ Mohamed Helmy Abdelhafeez
}

\begin{abstract}
Background: Substance use disorders (SUD) are considered as serious mental illnesses, with variability of age of onset, duration of illness, and type of used substance among patients. The effect of type and number of substances used on the severity of such an illness are worth scientific investigation.

In this study, we tried to investigate the probable relationship between type and number of used substances with the degree of severity of substance used disorders in a sample of upper Egyptian patients. To predict risk factors associated with the severity of SUD.

Results: Opiates (including tramadol) were the most frequently used substances followed by cannabis and then heroin. Patients using poly substances scored significantly higher than the ones using a single substance on AIS ( $p$ $=0.001)$, as well as on the legal, drug, and family and social subscales of ASI (0.012 0.006, 0.002 respectively). Multiple stepwise linear regression analysis demonstrated that the number of used substances was the most prominent factor in determining severity of substance-related disorder.

Conclusions: Using more than one substance is common in patients with substance use disorders. This is usually associated in more severe form and consequences of illness. So, some substances and combinations are associated with more morbidity than others.
\end{abstract}

Keywords: Substance use disorders, Severity, Type of substance, Poly-substance

\section{Background}

Addiction in the context of psychiatry has historically meant dysfunctional use of a substance that leads to psychosocial pathology. Over time, the concept has widened from illicit drugs to everyday necessities such as food, sex, and even technology such as the Internet [1].

The explanations of addiction might include those that suggest addicts to be motivated to take substances (crave) for one of two reasons. Drug craving is characterized by both the wish to go through the positive pleasurable effects of the drug and the desire not to

\footnotetext{
* Correspondence: abdelnaem2006@yahoo.com

Neurology \& Psychiatry Departments, Faculty of Medicine, Minia University, Minia, Egypt
}

\section{Springer Open}

(c) The Author(s). 2021 Open Access This article is licensed under a Creative Commons Attribution 4.0 International License, which permits use, sharing, adaptation, distribution and reproduction in any medium or format, as long as you give appropriate credit to the original author(s) and the source, provide a link to the Creative Commons licence, and indicate if changes were made. The images or other third party material in this article are included in the article's Creative Commons licence, unless indicated otherwise in a credit line to the material. If material is not included in the article's Creative Commons licence and your intended use is not permitted by statutory regulation or exceeds the permitted use, you will need to obtain permission directly from the copyright holder. To view a copy of this licence, visit http://creativecommons.org/licenses/by/4.0/. unpleasant consequences of withdrawal [2].

Chronic drug use has been associated with cognitive dysfunction, like poor decision making, grossly disturbed impulse control, and impaired performance of memory [3]. Frequent use of drugs over long time predisposes to poor behavioral coping with environmental difficulties likely due to lack of inhibitory control over behavior responses [4].

Examination of orientation showed that heroin addicts were significantly disoriented. Tasks to evaluate mental control were highly and significantly disturbed with heroin followed by benzodiazepine abuser. It was found that cannabis intake may lead to acute adverse mental effects on a dose-related level [5]. 
Individuals who start using substances early in life are more vulnerable to progressing to more hazardous substances and of developing drug use disorders [6]. Involvement in substance use escalates not only through progression from one substance to another (example, tobacco or alcohol to marijuana to other more illicit drugs) but also by increasing the rate of use of individual substances and serious changes in the contexts and patterns of use, in addition to the development of abuse and dependence [7].

The rate of using more than one substance concomitantly (poly-substance) varies across different studies done in Egypt. Rates as low as $21 \%$ of the total studied patients with substance use disorders were reported [8], up to $38.3 \%$ [9] and even $92 \%$ in the study more recently done by [10].

A study on poly-drug use compared to single-drug use group showed that poly-drug use group had significantly the worst outcome than the other one [11]. Those with poly-substance abuse are usually characterized by lower age of onset, regular use for longer duration, and lower response to treatment as measured by abstinence rates [12]. Such criteria render these patients more prone to greater levels of psychiatric problems as demonstrated by ASI subscales [13].

However, it is hypothesized that patients with a comorbid SUD or greater number of comorbid SUDs would be less likely to receive either buprenorphine or methadone treatment, although these same patients, with their greater burden of illness, would be more likely to access general SUD clinic services [14].

The present study had been done to investigate the probable relationship between type and number of used substances with the degree of severity of substance used disorders in a sample of upper Egyptian patients. To predict risk factors associated with the severity of SUD.

\section{Methods}

\section{Setting of the study}

Minia Hospital of Mental Health and Addiction Treatment is the official psychiatric hospital in Minia governorate (over 5 million people). It is located at New Minia city that is at north-east of the Nile. It provides services for psychiatric patients and patients of substance abuse. Its inpatient capacity is 50 beds (40 for male patients and 10 for female patients).

It provides an outpatient clinic service on daily basis and a Hot Line clinic for substance use disorder patients on twice weekly basis. Frequency of attendance to Hot Line clinic is around 20-30 clients per week. The Hot Line clinic is managed by three psychiatrists and two psychologists well trained in the field of addiction.
The management plan is carried out either through hospitalization or on outpatient basis by pharmacotherapy, psychotherapy (individual and group), and regular follow-up by phone calls with psychologists.

\section{Subjects of the study and size of the sample}

All clients attending outpatient addiction clinic of Minia Psychiatric Hospital in the duration of 6 months (between the 1st of December 2014 and 31st of May 2015) were subjected to screen for effect of substance abuse on the pattern of patients' lives and evaluation of severity of addiction.

Patients aged 18-60 years, whether males or females, with a positive history of substance use disorder were included in the study, provided that they gave oral and written consent to participate in the procedure of the study, while patients less than 18 or more than 60 years of age, those with chronic medical illness, those with acute intoxication or withdrawal symptoms or substance-induced psychosis, and those who refused to be involved in the study were excluded.

The final population sample of the present study included 103 patients of both sexes (95 males and 8 females) who had substance use disorder. They were diagnosed according to the Tenth Revision of the International Statistical Classification of Diseases and Related Health Problems, Diagnostic Criteria for Research (ICD10) [15].

The history of addiction is taken from each client and includes onset of addiction, probable causes of substance abuse, types, and amount of consumption of different substances, decision, and duration of periods of abstinence, number and factors behind relapse, causes of shifting from or adding one substance to another.

The agreement of the Ethical Scientific Committee of Minia Faculty of Medicine was obtained before the start of the research.

\section{Tools of the study Urine analysis screen for substances of abuse}

This was done in the Minia Hospital of Mental Health and Addiction Treatment laboratory by an experienced technician using 2 types of urine kits; the first is specific only for tramadol (DiaSpot Rapid One-step Test Device) and the second (ACON Urinalysis Reagent Strip) test for 6 different substances: THC (cannabis), BAR (barbiturate), COC (cocaine), AMP (amphetamine), MOP (morphine), and BZO (benzodiazepines).

\section{Addiction Severity Index (ASI) [16]}

The Addiction Severity Index (ASI) is a semi-structured interview originally made to assess in details problems presented by patients with substance use disorders. It was designed to guide primary treatment planning and 
allow follow-up of patient progress over time. Information is collected on seven functional areas mostly affected by substance use: medical status, employment and support, drug use, alcohol use, legal status, family and social status, and finally psychiatric status.

Each section includes questions about the duration, frequency and severity of problems over the whole patient's life and in the past 30 days. At the end of the assessment of each functional area, patients are asked to rate how troubled or annoyed they have been by these problems over the past 30 days and the degree to which they feel they need treatment. A $0-4$ scale is used for such ratings. For each functional area, the interviewer also makes severity ratings that reflect the magnitude of the interviewer's convection that patient needs additional treatment, on a scale from 0 to 9 [16].

The ASI has been extensively studied regarding joint reliability, test-retest reliability, and internal consistency of composite scores, with generally excellent results. Hodgings et al. [17] demonstrated average joint reliability scores of 0.89 . Concurrent, predictive, and discriminant validity have been demonstrated in a range of patient populations and treatment settings [18].

Table 1 Socio-demographic characteristics

\begin{tabular}{ll}
\hline Demographic data & Descriptive statistics $(\boldsymbol{n}=\mathbf{1 0 3})$ \\
\hline Age & $18-45$ \\
Range & $27.5 \pm 6.2$ \\
Mean \pm SD & \\
Male & $95(92.2 \%)$ \\
Female & $8(7.8 \%)$ \\
Residence & \\
Urban & $69(67 \%)$ \\
Rural & $34(33 \%)$ \\
Marital state & \\
Single & $49(47.6 \%)$ \\
Married & $51(49.5 \%)$ \\
Divorced & $3(2.9 \%)$ \\
Educational state & \\
Illiterate & $10(9.7 \%)$ \\
Basic education system & $81(78.6 \%)$ \\
Higher education system & $12(11.7 \%)$ \\
Occupational state & \\
Unemployed & $10(9.7 \%)$ \\
Manual worker & $69(67 \%)$ \\
Clerk & $16(15.5 \%)$ \\
Btudent & $4(3.9 \%)$ \\
\hline
\end{tabular}

\section{Addiction Intensity Scale (AIS)}

It is formed of 4 sections (moderate, severe, catastrophic, and terminal), and each one gives one point for each item checked and the total is calculated. If the score for each section is equal to or greater than the score in the parentheses below this score, this means that the examined subject meets the criteria for that level of addiction. The highest level for which one meets the criteria is his/her overall addiction intensity score (AIS).

The first step for anyone using the ERP (exposure and response prevention therapy) is to measure the intensity of your addiction. The Addiction Intensity Scale (AIS) can help [19].

\section{Data analysis and statistical methods}

The data collected were recorded on a separate file for each subject who was given a code.

Data analysis was done by the Statistical Package of Social Sciences (SPSS) Version 15.0 for Windows [20].

Table 2 Descriptive data of addiction characteristics

\begin{tabular}{|c|c|}
\hline Addiction characteristics & $\begin{array}{l}\text { Descriptive statistics }(n= \\
\text { 103) }\end{array}$ \\
\hline \multicolumn{2}{|l|}{ Duration } \\
\hline $1-5$ years & 45 (43.7\%) \\
\hline $6-10$ years & $41(39.8 \%)$ \\
\hline$>10$ years & $17(16.5 \%)$ \\
\hline \multicolumn{2}{|l|}{ Age of onset } \\
\hline$=18$ years & $41(39.8 \%)$ \\
\hline$>18$ to $<30$ years & $55(53.4 \%)$ \\
\hline$\geq 30$ years & $7(6.8 \%)$ \\
\hline \multicolumn{2}{|l|}{ Number of abused substances } \\
\hline One substance & $24(23.3 \%)$ \\
\hline Poly-substance & 79 (76.7\%) \\
\hline \multicolumn{2}{|l|}{ Substances of addiction } \\
\hline Alcohol & $24(23.3 \%)$ \\
\hline Heroin & $36(35 \%)$ \\
\hline Opiates (including tramadol) & $96(93.2 \%)$ \\
\hline Other sedative hypnotics & $36(35 \%)$ \\
\hline Cannabis & $66(64.1 \%)$ \\
\hline Hallucinogens & $6(5.8 \%)$ \\
\hline \multicolumn{2}{|c|}{$\begin{array}{l}\text { Addiction intensity scoring (according } \\
\text { to AIS) }\end{array}$} \\
\hline Moderate & $17(16.5 \%)$ \\
\hline Severe & $54(52.4 \%)$ \\
\hline Catastrophic & $29(28.2 \%)$ \\
\hline Terminal & $3(2.9 \%)$ \\
\hline
\end{tabular}

Most of the sample patients used more than one substance 
The data were summarized using the mean and standard deviation for quantitative data and percent for qualitative data.

Descriptive statistics of the study participants were conducted.

Fisher's exact test for qualitative data was used between each two groups like poly-substance and one substance groups and male and female groups.

Differences between studied groups were considered statistically at $P$ value $<0.05$.

\section{Results}

Table 1 shows that the sample included 69 subjects $(67$ $\%$ ) from urban areas. Fifty-one patients of the sample were married $(49.5 \%)$ while the rest were single or divorced. Only 10 patients $(9.7 \%)$ were illiterate, and the same number was unemployed at time of the interview.

Table 2 shows that only 17 patients $(16.6 \%$ of the sample) used to take substances for $>10$ years and 41 patients $(39.85 \%)$ started taking drugs at age $\leq 18$ years. Twenty-four patients $(23.3 \%)$ used only one substance, while poly-substance group included 79 patients (76.7\%).

The most prevalent substance used were opiates (93.2\%) followed by cannabis (64.1\%), heroin (35\%), sedative hypnotics (35\%) and alcohol (23.3\%) then hallucinogens (5.8\%).

More than half of the sample had severe (52.4\%) followed by catastrophic (28.2\%), moderate $(16.5 \%)$, then terminal $(2.9 \%)$ degrees.

Table 3 demonstrates that poly-substance group was distributed mainly in severe (50.6\%) and catastrophic

Table 3 Comparison between one-substance and poly-substance groups regarding severity of substance use illness

\begin{tabular}{|c|c|c|c|}
\hline & One substance $(n=24)$ & $\begin{array}{l}\text { Poly-substance } \\
N=79\end{array}$ & $P$ value \\
\hline \multicolumn{4}{|l|}{ Addiction intensity scoring (AIS) } \\
\hline Moderate & $9(37.5 \%)$ & $8(10.1 \%)$ & $0.001 *$ \\
\hline Severe & $14(58.3 \%)$ & $40(50.6 \%)$ & \\
\hline Catastrophic & $1(4.2 \%)$ & $28(35.4 \%)$ & \\
\hline Terminal & $0(0 \%)$ & $3(3.8 \%)$ & \\
\hline \multicolumn{4}{|l|}{ ASI scale } \\
\hline Medical subscale & & & 0.243 \\
\hline Median & 5 & 5 & \\
\hline IQR & $(2-5)$ & $(3-7)$ & \\
\hline Employment subscale & & & 0.958 \\
\hline Median & 5 & 5 & \\
\hline IQR & $(5-7)$ & $(5-7)$ & \\
\hline Legal subscale & & & $0.012^{*}$ \\
\hline Median & 1 & 1 & \\
\hline IQR & $(1-1)$ & $(1-5)$ & \\
\hline Alcohol subscale & & & 0.425 \\
\hline Median & 1 & 1 & \\
\hline IQR & $(1-1)$ & $(1-1)$ & \\
\hline Drugs subscale & & & $0.006^{*}$ \\
\hline Median & 5 & 7 & \\
\hline IQR & $(5-7)$ & $(5-9)$ & \\
\hline Family and social subscale & & & $0.002^{*}$ \\
\hline Median & 3 & 5 & \\
\hline IQR & $(3-7)$ & $(5-9)$ & \\
\hline Psychiatry subscale & & & 0.118 \\
\hline Median & 5 & 7 & \\
\hline IQR & $(5-7)$ & $(5-9)$ & \\
\hline
\end{tabular}

Fisher's exact test for qualitative data between the two groups. Mann-Whitney test for non-parametric quantitative data between the two groups $I Q R$ interquartile range

*Significant difference at $p$ value $<0.05$ 
Table 4 Comparison between scoring of Addiction Intensity Scale in patients with different main problematic substance

\begin{tabular}{|c|c|c|c|c|c|}
\hline & \multicolumn{5}{|c|}{ Main problematic substance } \\
\hline & Heroin $(n=30)$ & Tramadol $(n=42)$ & Opium $(n=11)$ & Cannabis $(n=6)$ & Tramadol + benzo $(n=14)$ \\
\hline \multicolumn{6}{|l|}{ Addiction Intensity } \\
\hline Moderate & $2(6.7 \%)$ & $9(21.4 \%)$ & $2(18.2 \%)$ & $3(50 \%)$ & $1(7.1 \%)$ \\
\hline Severe & $15(50 \%)$ & $25(59.5 \%)$ & $5(45.5 \%)$ & $2(33.3 \%)$ & $7(50 \%)$ \\
\hline Catastrophic & $12(40 \%)$ & $7(16.7 \%)$ & $4(36.4 \%)$ & $1(16.7 \%)$ & $5(35.7 \%)$ \\
\hline Terminal & $1(3.3 \%)$ & $1(2.4 \%)$ & $0(0 \%)$ & $0(0 \%)$ & $1(7.1 \%)$ \\
\hline$P$ value & 0.232 & & & & \\
\hline \multicolumn{6}{|c|}{ Comparison between pairs of substances } \\
\hline & Heroin $(n=30)$ & Tramadol $(n=42)$ & Opium $(n=11)$ & Cannabis $(n=6)$ & Tramadol + benzo $(n=14)$ \\
\hline Heroin $(n=34)$ & & 0.062 & 0.770 & 0.077 & 1 \\
\hline Tramadol $(n=63)$ & & & 0.537 & 0.326 & 0.238 \\
\hline Opiate $(n=11)$ & & & & 0.548 & 0.922 \\
\hline Cannabis $(n=55)$ & & & & & 0.262 \\
\hline
\end{tabular}

Fisher exact test for qualitative data between the two groups

*Significant difference at $p$ value $<0.05$

(35.4\%) subscales of AIS while one-substance group was distributed mainly in moderate $(37.5 \%)$ and severe (58.3\%) subscales. The comparison between onesubstance and poly-substance groups regarding AIS was highly statistically significant $(p=0.001)$.

There were also significant differences between onesubstance group and poly-substance group regarding some subscales of ASI. These were family subscale $(P=$ $0.002)$, drug subscale $(p=0.006)$, and legal subscale $(p=$ 0.012) (Table 3).

Table 4 shows that the frequencies of addiction intensity scale scoring had no significant difference between the main problematic used substances. In addition, there was no significant difference between an individual substance and another one as regards addiction intensity scale.

Positive and significant correlations were found between scoring of addiction intensity scale with duration of addiction, education level, total number of substances, and current number of substances, while a negative insignificant correlation was found between scoring of AIS and age of patients. However, a negative and significant correlation was found between scoring of AIS and age of onset of using substances (Table 5).

Simple linear regression analysis was done and revealed that the overall number of substances was the main predictor of the score of addiction intensity scale $\left(R^{2}=0.242, p=<0.001\right)$ followed by age of onset $\left(R^{2}=\right.$ $0.102, p=0.001)$, education duration in years $\left(R^{2}=\right.$ 0.073, $p=0.006)$, duration of addiction $\left(R^{2}=0.058, p=\right.$ $0.014)$, and current number of substances $\left(R^{2}=0.041, p\right.$ $=0.039$ ).

Multiple linear regression analysis predicting the score of addiction intensity scale revealed that overall number of substances, education level, and age of onset of addiction were the significant predictors of addiction intensity. On the other hand, stepwise multiple linear regression analysis controlling for the interrelations between predictors revealed that overall number of substances $(p \leq 0.001)$, education $(p=0.017)$ had shared a unique contribution in predicting the score of addiction intensity scale (Tables 6 and 7).

\section{Discussion}

More than half of the sample (53.4\%) started taking substances at age ranging from 18 to 30 years, while 41 patients $(39.85 \%)$ started at the age of 18 years and only $6.8 \%$ started to take drugs above 30 years. This result agreed with Abd El-Azim [21] who stated that the progression of age decreased markedly the liability to take substance. In addition, the same authors reported that $46.8 \%$ of their patients started to abuse cannabis and alcohol around the age of 15-17, which is the age of trying and peer pressure.

Table 5 Correlations between Addiction Intensity Scale (AIS) scoring and some clinical and addictive characteristics

\begin{tabular}{lll}
\hline & \multicolumn{2}{l}{ Addiction intensity score } \\
\cline { 2 - 3 } & $\boldsymbol{R}$ & $\boldsymbol{P}$ value \\
\hline Age of patients & -0.073 & 0.462 \\
Age of onset & -0.319 & $\mathbf{0 . 0 0 1 ^ { * }}$ \\
Duration of addiction & 0.241 & $\mathbf{0 . 0 1 4 ^ { * }}$ \\
Education & 0.270 & $\mathbf{0 . 0 0 6 ^ { * }}$ \\
Total number of substances & 0.492 & $<\mathbf{0 . 0 0 1 ^ { * }}$ \\
Current number of substances & 0.203 & $\mathbf{0 . 0 3 9 ^ { * }}$ \\
\hline
\end{tabular}

Pearson's correlation

*Significant correlation at $p$ value $<0.05$ 
Table 6 Multiple linear regression analysis to detect the predictors affecting Addiction Intensity Scale (AIS) scoring

\begin{tabular}{|c|c|c|c|c|c|}
\hline & \multicolumn{2}{|c|}{ Unstandardized coefficients } & \multirow[t]{2}{*}{$R$} & \multirow[t]{2}{*}{$R^{2}$} & \multirow[t]{2}{*}{$P$ value } \\
\hline & $B$ & Std. error & & & \\
\hline Constant & 13 & 2 & 0.580 & 0.337 & $0.040^{*}$ \\
\hline Age of onset & -0.14 & 0.07 & & & 0.849 \\
\hline Duration of addiction & 0.02 & 0.08 & & & $0.013^{*}$ \\
\hline Education & 0.2 & 0.08 & & & $<0.001 *$ \\
\hline Overall number of substances & 1.28 & 0.29 & & & 0.057 \\
\hline Current number of substances & -0.77 & 0.4 & & & \\
\hline
\end{tabular}

Multiple linear regression analysis

The sample of our study was divided into two groups: poly-substance group which represents the majority of patients $(n=79 ; 76.7 \%)$ and one substance group which included only 24 patients (23.3\%). These results were like those obtained by Abou Khatwa and colleagues [22], who studied 92 patients admitted to the addiction ward at Mammoura Hospital. He stated that the majority of addicts were poly-drug users. Abd El-Azim and colleagues [21] revealed that $87.7 \%$ of his sample subjects were using poly-substance. These results were nearly close to those obtained by El-Awady and colleagues [10] who stated that the majority of their studied addicts were abusing more than one drug $(n=92 ; 92 \%)$ while the rest were abusing one substance $(n=8 ; 8 \%)$.

On the other hand, these results were inconsistent with the results obtained by Khalil and colleagues [8] who found that only $21 \%$ of patients reported polysubstance use. Mohamed and colleagues [9] mentioned in their study that the poly-drug use was present in only $38.3 \%$ of the patients. Mohamed and colleagues [23] revealed that the prevalence of poly-substance abusers in their study group was $43.94 \%$ of the patients.

Our results show that the most prevalent substance used were opiates $(93.2 \%)$ mainly tramadol followed by cannabis $(64.1 \%)$, heroin (35\%), sedative hypnotics (35\%) and alcohol (28.2\%) then hallucinogens (5.8\%). These results were nearly similar to the results reported by Mohamed et al. $[9,23]$ who reported that tramadol was the most prevalent substance followed by cannabis.

Also, Lin and colleagues [14] found that comorbid SUDs are highly prevalent among patients with OUD but, on average, are associated with a lower likelihood of patients receiving buprenorphine treatments for OUD, but with higher likelihood of patients accessing any outpatient SUD treatment.

There was a study nearly like ours and showed that tramadol was the most frequently used substance (97\%) followed by cannabis, sedatives, and hypnotics (38\%); alcohol (32\%); heroin (30\%); and anticholinergic drugs (12\%) [10]. Tramadol is considered the most prevalent substance in many studies because it is relatively cheap, available in many forms and different illegal forms present in market, so it is easy to be obtained.

However, Eid [24] demonstrated that cannabis was the most common substance used while tramadol was the least common, as well as Mikhail and colleagues [25] who found that cannabis was the most prevalent followed by codeine. These results are due to unavailability of tramadol in that period as it began to appear and be popular in the last 10 or 12 years.

Forty-two patients considered the main problematic substance for them was tramadol, thirty patients considered heroin, fourteen patients considered tramadol + benzodiazepine, eleven patients considered opium, and cannabis was considered by six patients. These results were inconsistent with the results obtained by Khalil and colleagues [8] showing that heroin (52\%), other opiates (23\%), sedative/hypnotics or cannabis (7\% for each), alcohol (4\%), amphetamines (2\%), and hallucinogens $(2 \%)$ were the main problematic substances.

In addition, these results were inconsistent with those of Abd El-Azim, Okasha, Hatata, and Olson et al. [21, 26-28]. They found that the substance of major problem was opioids, followed by cannabis, and most participants in their studies had poly-drug abuse during the entire course of illness. The difference between our results and

Table 7 Multiple stepwise regression analysis to detect predictors affecting Addiction Intensity Scale (AIS) scoring

\begin{tabular}{|c|c|c|c|c|c|c|}
\hline \multirow[t]{2}{*}{ Model } & & \multicolumn{2}{|c|}{ Unstandardized coefficients } & \multirow[t]{2}{*}{$R$} & \multirow[t]{2}{*}{$R^{2}$} & \multirow[t]{2}{*}{$P$ value } \\
\hline & & B & Std. error & & & \\
\hline 1 & $\begin{array}{l}\text { Constant } \\
\text { Overall number of substances }\end{array}$ & $\begin{array}{l}10.8 \\
1.2\end{array}$ & $\begin{array}{l}0.7 \\
0.2\end{array}$ & 0.492 & 0.242 & $<0.001^{*}$ \\
\hline 2 & $\begin{array}{l}\text { Constant } \\
\text { Overall number of substances } \\
\text { Educational }\end{array}$ & $\begin{array}{l}9.1 \\
1.14 \\
0.19\end{array}$ & $\begin{array}{l}1 \\
0.21 \\
0.08\end{array}$ & 0.534 & 0.285 & $\begin{array}{l}<0.001^{*} \\
0.017^{*}\end{array}$ \\
\hline
\end{tabular}


theirs could be justified by the differences in the place and timing of these different studies.

Our study showed that the poly-substance group was distributed mainly in severe (50.6\%) and catastrophic (35.4\%) subscales of AIS while one-substance group was distributed mainly in moderate (37.5\%) and severe (58.3\%) subscales. The comparison between the two groups scoring on Addiction Intensity Scale showed that those with poly-substance scored significantly worse on AIS $(p=0.001)$. These results were close to another study on the effect of the number of used substances on outcome, where poly-drug use group had significantly the worse outcome than the single substance group [11].

Our sample of poly-substance patients scored worse on all subscales of ASI when compared with onesubstance group. The differences were statistically significant for family subscale $(P=0.002)$, drug subscale $(p$ $=0.006)$, and legal subscale $(p=0.012)$.

This can be compared with the results reported by Schrimsher and colleagues [13] who mentioned that multiple substance use was significantly related to greater levels of psychiatric problems as identified by the Addiction Severity Index.

In addition, these results are less intense than those reported by another study which found an evident difference between poly-substance use and single substance use as regard all domains of ASI. The correlations were statistically significant for all the ASI domains (medical, employment, alcohol use, drug use, legal problems, family and social relationships, and psychological domains) [12].

This could be explained on the ground that multiple drug abuse is usually associated with severe conditions of psychopathological nature, positive family history for substance abuse, and presence of marked mental health problem, in addition to the need to manage emotions. All these factors lead to more severe form of substance use disorders [11]. In addition, the use of multiple substances is reported to be associated with lower age of onset, regular use for long time, and lower abstinence rates after treatment. Therefore, such patients experience severe complications as measured by ASI subscales [12].

\section{Conclusions}

Using more than one substance is common in patients with substance use disorders. This is usually associated in more severe form and consequences of illness. Some substances and combinations are associated with more morbidity than others.

\section{Abbreviations}

AMP : Amphetamine; ASI: Addiction Severity Index; AIS: Addiction Intensity Scale; BAR : Barbiturate; BZO: Benzodiazepines; COC: Cocaine;
MOP: Morphine; OUD: Opioid used disorder; SUD: Substance use disorder; SPSS: Statistical Package of Social Sciences; WHO: World Health Organization

\section{Acknowledgements}

We need to thank all subjects who agreed to participate in our study and gave us much of their time and interest.

\section{Authors' contributions}

All authors participated in a meaningful way in the preparation of the manuscript, MAE had filled the questioners and collected the data, MAH had chosen the tools and analyzed the data, MAA wrote the manuscript after data analysis, and MHA has revised the Manuscript. All authors have read and approved the final manuscript.

\section{Funding}

This research did not receive any specific grant from funding agencies in the public, commercial.

\section{Availability of data and materials}

The datasets generated and/or analyzed during the current study are available from the corresponding author on reasonable request.

\section{Declarations}

Ethics approval and consent to participate

Study approval was from the research ethics committee of the Faculty of Medicine, Minia University (Number: 12539068). An oral and written consent was obtained from the patients who participated in this research.

\section{Consent for publication}

All participants approved the submission and publication.

\section{Competing interests}

The authors declare that they have no competing interests.

Received: 29 January 2021 Accepted: 24 July 2021

Published online: 06 August 2021

\section{References}

1. Sdrulla AD, Chen G, Mauer K. Definition and demographics of addiction. In: Kaye A, Vadivelu URD, editors. Substance abuse inpatient and outpatient management for every clinician. New York: Springer; 2015. p. 1-17.

2. Robinson TE, Berridge KC. The psychology and neurobiology of addiction: an incentive-sensitzation view. Addiction. 2000:95:91-11.

3. Rogers RD, Robbins TW. Investigating the neurocognitive deficits associated with chronic drug misuse. Curr. Opin. Neurobiol. 2001;11(2):250-7. https:// doi.org/10.1016/S0959-4388(00)00204-X

4. Bechara A. Decision making, impulse control and loss of willpower to resist drugs: a neurocognitive perspective. Nat. Neurosci. 2005;8(11):1458-63. https://doi.org/10.1038/nn1584.

5. Salem SS, Wahab MA, Shaheen MO, Husin NM. Cognitive impairment among drug abuser. An Egyptian study, Cairo University; 2003.

6. Grant BF, Dawson DA. Age of onset of drug use and its association with DSM-IV drug abuse and dependence. J Subst Abuse. 1998;10(2):163-73. https://doi.org/10.1016/S0899-3289(99)80131-X.

7. Lynskey MT, Health AC, Bucholz KK, Slutskey WS, Madden PA, Nelson EC, et al. Escalation of drug use in early onset cannabis users vs. co-twin controls. JAMA. 2003;289(4):427-33. https://doi.org/10.1001/jama.289.4.427.

8. Khalil A, Okasha T, Mansour SM, Haroon A, El Habiby M, Carise D. Characterization of substance abuse patients presenting for treatment at a University Psychiatric Hospital in Cairo, Egypt. Addict Disord Their Treat. 2008:8:199-209.

9. Mohamed NR, Hammad SA, El Hamrawy LG, Rajab AZ, El Bahy MS, Soltan MR. Dual diagnosis and psychosocial correlates in substance abuse in Menoufia, Egypt. Menoufia Med. J. 2013;26:114-21.

10. El-Awady SA, El sheshtawy EA, El bahaey WA, El boraie OA. Impact of familial risk factors on the severity of addiction in a sample of Egyptian adolescents. Egypt J Psychiatr. 2017;38(2):70-8. https://doi.org/10.4103/111 0-1105.209677.

11. Alvarez-Alonso MJ, Jurado-Barba R, Martinez-Martind N, Espin-Jaime JC, Jimenez-Arriero J, Manzanares G. Association between maltreatment and 
polydrug use among Adolescents. Child Abuse Negl. 2016;51:379-89. https://doi.org/10.1016/j.chiabu.2015.07.014.

12. Raes V, Maeyer JD, Vanderplasschen W, Lammertyn J. Poly substance use, mental health and related problems among persons seeking treatment in De Sleutel. In: Vanderplasschen W, Maeyer JD, Colpaert K, Cogels S, Rea A,

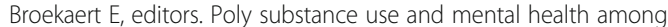
individuals presenting for substance abuse treatment. Europe: Academia press; 2011. p. 91-110.

13. Schrimsher GW, Parker JD, Burke RS. Relation between cognitive testing performance and pattern of substance use in males at treatment entry. Clin Neuropsychol. 2007;21(3):498-510. https://doi.org/10.1080/138033 90600674441.

14. Lin LA, ASB B, Blow FC, Gordon AJ, Ignacio RV, Kim HM, et al. Polysubstance use and association with opioid use disorder treatment in the US Veterans Health Administration. Addiction. 2021;116,1:96-104.

15. World Health Organization. International statistical classification of diseases and related health problems, 10th edition (ICD10). Geneva: Vol.1. 1995.

16. McLellan AT, Lubrosky L, Woody GE, Brien CP. An improved diagnostic evaluation instrument for substance abuse patients, The Addiction Severity Index. J Nerv Ment Dis. 1980;168(1):26-33. https://doi.org/10.1097/ 00005053-198001000-00006.

17. Hodgings DC, El-Guebaly N, Armstrong S, Dufour M. Implications of depression on the outcome of alcohol dependence: 3 years prospective,Alcohol Clin Exp Res.1999;23(1):151-7.

18. McLellan AT, Lubrosky L, Cacciola J, Griffith J, Evans F. New data from Addiction Severity Index. Reliability and validity in three centers. J Nerv Ment Dis. 1985;173(7):412-23. https://doi.org/10.1097/00005053-19850700000005.

19. Baker TB, Morse E, Sherman JE. The motivation to use drugs: a psychobiological analysis of urges. In: Rivers C, editor. The Nebraska Symposium on Motivation: alcohol use and abuse. Lincoln: University of Nebraska Press; 1987. p. 257-323.

20. Statistical Package of Social Sciences (SPSS) Version 15.0 for Windows Chicago: SPSS Inc.; 60606-6412. 2006.

21. Abd El-Azim KA. Psychosocial correlates of substance abuse (a study in an Egyptian sample). Unpublished MD thesis. Faculty of Medicine, Ain Shams University; 2001.

22. Abou Khatwa S, Kamel F, Youssef R, Attia M, Fawal K. Epidemiological study of addicts admitted to Maamoura psychiatric hospital in Alexandria. J Egypt Public Health Assoc. 1997;22:88-112.

23. Mohamed NR, El Hamrawy LG, Shalaby AS, El Bahy MS, Abd Allah MM. An epidemiological study of tramadol $\mathrm{HCl}$ dependence in an outpatient addiction clinic at Heliopolis Psychiatric Hospital. Menoufia Med. J. 2015;28: 591-6.

24. Eid H. Substance dependence in a sample of Egyptian adolescents. Unpublished MD Thesis. Faculty of Medicine, Cairo University; 2006.

25. Mikhail M, Eissa MA, Labeeb SHA, El-Hamid SM. The Psychosocial Aspects of Drug Addicts in Assiut Governorate. Bull. Environ. Stud. 2001;4:33-44.

26. Okasha A. Substance use in a major public health hazard. Proceedings of the First Egyptian International Conference on Addiction and Drug Abuse. Cairo: Ministry of Health; 1997.

27. Hatata HA. Dual diagnosis in substance use disorders. Unpublished MD thesis. Faculty of Medicine, Ain Shams University; 2004.

28. Olson VG, Heusner CL, Bland RJ, During MJ, Weinshenker D, Palmiter RD. Role of noradrenergic signaling by the nucleus tractus solitarius in mediating opiate reward. Science. 2006;311(5763):1017-20. https://doi.org/1 $0.1126 /$ science.1119311.

\section{Publisher's Note}

Springer Nature remains neutral with regard to jurisdictional claims in published maps and institutional affiliations.

\section{Submit your manuscript to a SpringerOpen ${ }^{\circ}$ journal and benefit from:}

- Convenient online submission

- Rigorous peer review

- Open access: articles freely available online

- High visibility within the field

- Retaining the copyright to your article

Submit your next manuscript at $\boldsymbol{\nabla}$ springeropen.com 